Social Integration of Older Immigrants in 21st Century America

Janet M. Wilmoth

No. 29/2004 
Janet M. Wilmoth is associate professor of sociology and senior research associate, Center for Policy Research, Maxwell School of Citizenship and Public Affairs, Syracuse University. Her research focuses on migration and living arrangements, social support, and health status among older adults.

The Policy Brief series is a collection of essays on current public policy issues in aging, health, income security, metropolitan studies, and related research done by or on behalf of the Center for Policy Research (CPR) at the Maxwell School of Syracuse University.

Single copies of this publication may be obtained at no cost from the CPR Web site at http://wwwcpr.maxwell.syr.edu or from the Center for Policy Research, 426 Eggers Hall, Syracuse, NY 132441020.

(C) 2004, Syracuse University. This publication may be distributed freely for educational and researcher uses as long as this copyright notice is attached. No commercial use of this material may be made without express written permission. 
Policy Brief

Social Integration of Older Immigrants in 21st Century America

Janet M. Wilmoth 


\section{Social Integration of Older Immigrants in 21st Century America}

There are various reasons for the burgeoning interest in detailed research into the determinants of social well-being among older immigrants in this country. As a result of shifting federal government policies, the total volume of immigrants has increased significantly, the countries from which they migrate have changed, and more immigrant families have brought their parents into the United States than ever before. Consequently, the older adult population is becoming more diverse due in part to the aging-in-place of younger immigrants and an increasing number of immigrants who are older upon arrival in the United States. These trends create challenges for social service providers, who are encountering language and cultural differences among their clients for which they are unprepared.

This report provides an overview of research about older adult immigrants in the United States that my colleagues and I have conducted over the past few years. Various demographic and cultural aspects of today's immigrants that differ from the past are described. The importance of social integration to older immigrants' well-being is considered. Then some intriguing research about the "new immigrants" is summarized and additional areas for future research are suggested. 
Aging Studies Policy Brief

\section{Background}

\section{Federal Statutes and Policies Affecting Recent Immigration}

Immigration into the United States is governed by federal law. As Ruth Ellen Wasem $(2003,1)$ writes in "Immigration and Naturalization Fundamentals,"

Four major principles underlie [current] U.S. policy on legal permanent immigration: the reunification of families, the admission of immigrants with needed skills, the protection of refugees, and the diversity of admissions by the country of origin.

The modern Immigration and Nationality Act was enacted in 1952 and amended several times since. In 1965 Congress replaced the national origins quota system, which was heavily weighted to favor immigrants from northern and western European countries, with a preference system that favored family members and immigrants with needed skills. The 1980 Refugee Act (P.L. 96-212) established the Federal Refugee Program, a formal system of refugee admissions and settlement following the Vietnam War. (Refugees change to immigrant status after one year of residence in the United States.) The Immigration Reform and Control Act of 1986 established legalization programs to regularize the status of certain illegal aliens who had resided continuously in the U.S. since before January 1, 1982, while also criminalizing the hiring of illegal aliens. These laws, by eliminating numerical restrictions on immediate relatives of U.S. citizens, including naturalized citizens, encouraged the reunion of older parents from overseas with their adult children in the U.S., and released the pent-up demand for immigration from Asian countries that had previously been prohibited or tightly limited.

Recent Changes in the Immigrant and Naturalized Citizen Population

Immigrants, as defined by U.S. immigration law, are persons lawfully admitted for permanent residence in the United States. (U. S. Department of Homeland Security 2004a) 
The number of immigrants entering the United States is greater now than it has been in several decades, fueled primarily by an increase in numerically restricted immediate relatives of U.S. citizens, including newly naturalized citizens (Vialet 1997, 6). Between 1991 and 2000 ,over 9 million immigrants entered the country, only slightly more than the 8,795,000 who arrived between 1901 and 1910. About 700,000 legal immigrants were admitted in 2003; of these, 5 percent $(37,176)$ were age 65 or older (U.S. Department of Homeland Security 2004a, table 2).

Figure 1. Annual Immigrant Admissions and Status Adjustments, 1900-2001

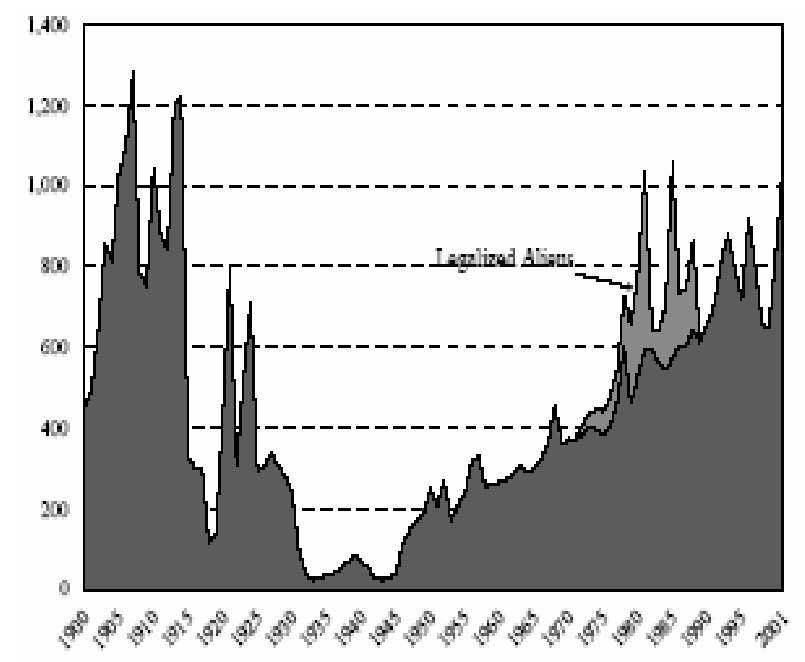

Source: Wasem 2003, figure 1. This figure uses data from the Bureau of Citizenship and Immigration Services (BCIS) of the Department of Homeland Security and includes only legally admitted aliens.

Since 1925 the portion of immigrants from Europe has shrunk, while the portion of immigrants from Asia has grown substantially (see figure 2). In 2003, nearly 35 percent of immigrants came from Asia, 16 percent from Mexico, 15 percent from Central and South America, and 14 percent from Europe (U.S. Department of Homeland Security 2004a, table 8). 
Aging Studies Policy Brief

Figure 2. Legal Immigrants by Region of Birth: Fiscal Years 1925-2003

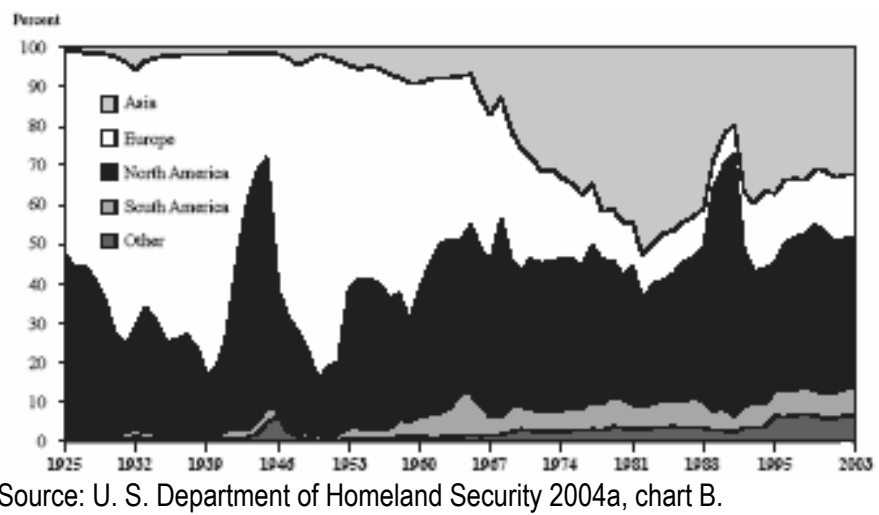

Proportion of Population Born Outside the U.S.

Figure 3. Foreign-Born Residents of the United States, 1870-2002

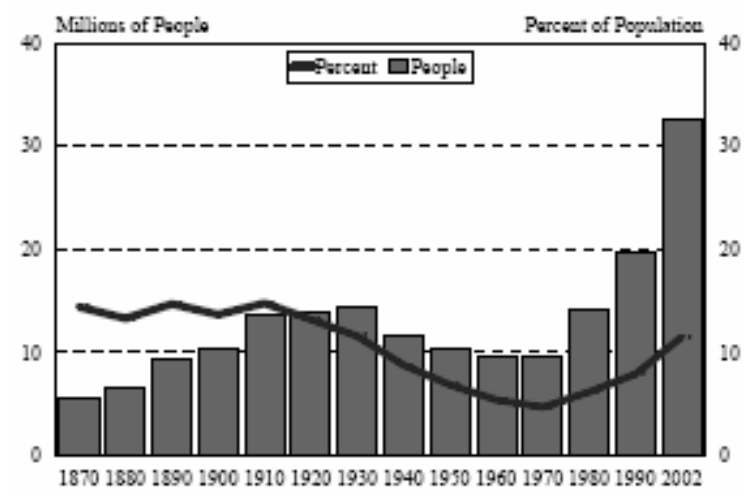

Source: Wasem 2003, figure 2. These Census Bureau data include legal immigrants, refugees, asylees, temporary alien residents, and illegal aliens.

First, note that the overall population increase in the United States between 1990 and 2000, 32.7 million people, was the largest in a single decade in American history; compare it to 28.0 million people between 1950 and 1960, a decade in the middle of the post-World War II baby boom (Perry et al. 2001). 
At the same time, several decades of immigration have increased the sheer number of foreign born residents of the United States to its highest point in U.S. history: 33.5 million people (11.7 percent of the population) in the United States are foreign born (Larsen 2004). And nearly three-fourths of them arrived since 1980. Of the foreign born, 53.3 percent are from Latin America, 25.0 percent from Asia, 13.7 percent from Europe, and the rest from other areas of the world.

The foreign born population is different from the native born population in several ways that shape the aging experience and the need for social services in later life:

- Native born Americans age 65 and over make up 12.1 percent of the native born population; foreign born residents age 65 constitute a slightly smaller portion, 11.1 percent, of the foreign born population.

- Comparing family size, only 12.5 of native born American families contain five or more people, compared to 9.8 percent of those where the householder was born in Europe, 19.2 percent of those born in Asia, 32.9 from Latin America, and 39.3 percent from Central America.

- For educational attainment, 87.5 percent of native born Americans have at least a high school education in 2003, compared to 84.9 percent of those born in Europe, 87.4 percent of those born in Asia, 49.1 percent from Latin America, and 37.7 from Central America.

- Household income data suggest that while overall the differences between the proportion of native born residents and foreign born residents in each of three income brackets (less than $\$ 20,000 ; \$ 20,000$ to $\$ 49,000$; and $\$ 50,000$ or greater) is not large $(22.3 / 33.7 / 44.0$ percent for native born compared to 24.6/36.8/38.6 percent for all foreign born), there are significant differences by region of birth. Those born in Asia have the smallest percentage of low-income households (18.5 percent) and, at the other end, the largest percentage of high-income households (53.8 percent). Those from Latin American have the largest portion of low-income households (28.0 percent) and the third lowest portion of high-income households (29.0 percent).

- The poverty rate for foreign born individuals is 5 percentage points higher than for native born individuals, but again this aggregate obscures large differences: 11.1 percent for those from Asia, compared 
Aging Studies Policy Brief

to 21.6 from Latin America, and 23.6 percent for those from Central America.

Included among the foreign born are about 7 million illegal aliens who resided in the United States in January 2000, up from 3.5 million a decade earlier, according to estimates of the U.S. Immigration and Naturalization Service (INS 2003). Not a great deal is known about this group of people, including how many of them are age 65 or older.

\section{Policies That Affect Older Immigrants}

\section{Sponsorship}

Families who decide to bring extended family members into this country are undertaking a substantial financial obligation. Effective December 1997, someone who wants to bring a family member to live in the United States must file a legally binding affidavit of support that commits the sponsor to provide financial support for the immigrant until that person becomes a U.S. citizen (usually five years) or can be credited with 40 quarters of work (usually ten years) (Wasem 2003). The sponsor must prove that he or she has adequate income to make this guarantee, which the government defines as at least 125 percent above the U.S. poverty line for a household of that size, including the new immigrant and all past sponsored immigrants. Sponsors with low income can add the cash value of their assets, worth at least five times the amount up to the minimum income requirement, and the assets of other household members and the immigrant as well. (See U. S. Department of Homeland Security 2004b.) If the immigrant subsequently receives any "means-tested public benefits" the sponsor must repay the cost of the benefits and can be sued by the government to enforce this obligation.

\section{Welfare Reform}

The Personal Responsibility and Work Opportunity Reconciliation Act of 1996 (PRWORA; P.L. 104-193) rescinded the eligibility of most legal aliens for Supplemental Security Income (SSI) for the Aged, Blind, or Disabled, and for Food Stamps - in many cases terminating existing benefits. This law also allows states to limit immigrants' access to Medicaid and Temporary Assistance for Needy Families (TANF). Most legal aliens who arrived after PRWORA was enacted were barred from most federal means-tested programs for 5 years after 
arrival. After 5 years, the sponsor's income is deemed to be available to new immigrants in determining their financial eligibility for designated federal means-tested programs until they naturalize or meet the work requirement (Wasem 2003). Congress has since passed laws to continue or partially restore eligibility for SSI, Medicaid, and Food Stamps for older or disabled aliens.

\section{Naturalization}

To be eligible to apply for naturalization, permanent legal residents must have continuously resided in the United States for 5 years; demonstrate good moral character; be able to read, write, speak, and understand English; and pass a civics exam. The language requirement is waived for those who are at least 50 years old and have resided here for at least 20 years (or 55 years old and have resided here for 15 years). Immigrants over 65 years of age who have lived here for at least 20 years receive special consideration on the civics exam. Both requirements are waived for those who are cannot comply due to developmental disabilities or mental impairment (Wasem 2003). The fee for the N-400, application for naturalization, which was $\$ 95$ in the mid-1990s and increased in January 1999 to $\$ 225$, is now $\$ 320$. One rationale for the fee increase was to reduce the tremendous backlog of unprocessed applications; however, an applicant must still wait 6-10 months, and "it is not uncommon for some [immigrants] to wait 1-2 years for their petitions to be processed" (Wasem 2003).

The new benefits regulations may have pressured immigrants, many of whom have lived in this country for decades as resident aliens, to take the final step of applying for citizenship. In 1993, the INS received only 521,886 applications; in 1997, just after PRWORA was implemented, INS received nearly 1.6 million naturalization applications, about three times as many applications as just four years earlier (Angus 1998, 2).

\section{Implications}

These policies place increased responsibility on immigrant families to provide financial, instrumental, and personal care support for their older members. It seems likely that immigrants who are sponsored by families with very limited resources will reside with family members. In some cultures with a filial piety tradition, such living arrangements may be expected and desirable. But there is limited empirical evidence 
of whether, and which, older immigrants actually bring this expectation with them to the United States, or how their expectations interact with the family's expectations, their contractual obligation to provide support, and their potentially limited resources. There is also limited evidence regarding how these policies affect the well-being of immigrant families in general and older immigrants in particular. It is expected that the degree to which the older adult is socially integrated has a substantial impact on the physical and mental health outcomes of older immigrants.

\section{Social Integration Theory and Older Adults}

Irving Rosow wrote the classic statement of social integration theory as it applies to older persons in his 1967 book, Social Integration of the Aged.

Integration...concerns how the person is tied into the webs of belief and action in his society.

The integration of individuals into their society results from forces which place them within the system and govern their participation and patterned association with others. This network of bonds has three basic dimensions: (1) social values, (2) formal and informal group memberships, and (3) social roles. Thus, people are tied into their society essentially through their beliefs, the groups that they belong to, and the positions that they occupy. In general, to the extent that older people can preserve their middle age patterns in these areas, then they maintain the basis of their social integration. That is, insofar as their lives do not change in old age. But to the extent that their lives $d o$ change and they cannot maintain their earlier patterns, then their integration may be undermined. The crucial factor is not the absolute state of their associations so much as the sheer disruption of their previous life style, activities, and relationships. In general, the greater the change, the greater the risk of personal demoralization and alienation from society.

...[T]here are endemic forces in modern life which seem to alienate old people as a sheer function of their aging. 
Although their beliefs do not significantly change in the later years, older people's social integration is steadily weakened on the other two crucial dimensions: the loss of their social roles and group memberships. These are almost irrevocably undermined, so that the basis of their social participation is eroded. (Rosow 1967, 8-10)

There has been much research about social integration and mental health among older adults that emphasizes social roles and group memberships (see Wilmoth and Chen 2003). Because this literature focuses mainly on people who live and die in their home country, their underlying beliefs, which may change somewhat from cohort to cohort, are assumed to remain relatively constant across the life course.

The research described in this policy brief, however, concerns people who lost that national assumed cultural environment when they immigrated to the United States. Some settled in densely populated cultural enclaves within the United States that allowed them to preserve their language and culture inside the group but helped isolate them even further from those outside the group, the so-called dominant culture. Others discovered that the values they took for granted no longer apply in their new country, and the backdrop against which they live their lives is unfamiliar and expressed in a language they do not understand. This not only undermines older immigrants' social values but can limit their group memberships and social roles. Therefore, older immigrants are particularly vulnerable to not being socially integrated. This should be particularly true of immigrants who were older upon arrival in the United States because immigration later in life creates a substantial disruption of the older adult's previous lifestyle, activities, and relationships.

Social roles and attachments are essential to well-being in later life (Pillemer, Glasgow, Moen, and Wethington 2000). Social integration offers opportunities to develop supportive relationships, increases access to coping resources, and provides meaning to life. This in turn minimizes stress and improves mental health, particularly in later life when there is diminished participation in the social roles that promote social integration (George 1996). This suggests that older immigrants who are not socially integrated may be at risk of poor physical and mental health outcomes. 
Aging Studies Policy Brief

There are various indicators of social integration, one of which is living arrangements (Pillemer et al. 2000). This report will now review three studies my colleagues and I have conducted that examine the distribution of living arrangements and the effect of those arrangements on mental health among older immigrants.

\section{Current Research}

\section{Wilmoth, DeJong, and Himes 1997}

In 1997 we compared living arrangements between immigrants and non-immigrants among the white, Hispanic, and Asian older population (Wilmoth, DeJong, and Himes 1997), using data from the 1990 5\% Public Use Microdata Sample (PUMS) of the U.S. Census Bureau, which contains household and individual level information from the long-form questionnaires distributed to about one in six households during the decennial census. A $10 \%$ random sample of white correspondents from the PUMS was drawn, totaling nearly 200,000 whites age 60 and over. Another sample of records for all older minority respondents age 60 or over was extracted. We grouped living arrangements for this analysis into three categories: independent (living alone or with a spouse), extended family (living with children or other relatives), and non-family (living with non-kin).

We determined immigrant status by citizenship and year of entry into the United States: for this study, immigrants are defined as individuals who were citizens of another country at birth and later moved to the United States. We calculated age at immigration from age in 1990 and year of immigration, and constructed from this a dummy variable to identify those who immigrated before age 60 and those who immigrated at age 60 or older.

Respondents self-identified their race/ethnicity: non-Hispanic white, Hispanic (of any race), and Asian. We would have preferred a more refined breakdown but it was not available. We excluded Blacks and Native Americans because there were not enough immigrants, especially older immigrants, in these groups.

We included variables of income, functional limitations, acculturation, and demographic factors because previous research (cited in Wilmoth et al. 1997) suggests that they are important factors in determining older adult living arrangements. We discussed alternative hypotheses 
for the impact of income, or economic resources, on older people's living arrangements. The functional limitations available to us were based on the question: "Because of a health condition that has lasted 6 or more months, does this person have any difficulty (a) going outside the home alone, for example, to shop or visit a doctor's office? or (b) taking care of his or her own personal needs, such as bathing, dressing, or getting around the house?" The responses were coded as: having either a mobility or personal care limitation, having both limitations, or having no limitations.

We included English language proficiency (good or poor) as a proxy for acculturation, because an immigrant who can speak English can interact more easily and independently with the dominant culture.

The demographic controls included age, gender, marital status, and education, but nothing about family structure that would suggest, for example, the availability of adult children to provide informal care.

We first used these measures for a descriptive analysis that identifies the characteristics of the three groups: older non-immigrants, older immigrants who were less than age 60 when they immigrated, and immigrants who were age 60 or older when they immigrated. Then we specified multinomial logistic models for non-Hispanic white, Hispanic, and Asian older adults to identify the contribution of the variables to differences between the immigrant and non-immigrant groups.

Among all racial/ethnic groups, those who immigrated at age 60 or older were more likely to be female, have less education, have more functional limitations, and were older than the non-immigrant elders. Those immigrants who arrived before age 60 were midway between the other two groups; they are also more acculturated. Looking at racial/ethnic groups, the Hispanic immigrants are the least acculturated and have the least amount of education, while Asian immigrants are the youngest and have the lowest incidence of functional limitations.

Finally we observed living arrangements by race/ethnicity and immigrant status. As expected, immigrants across all races/ethnicities were less likely to live independently than non-immigrants. This trend is more pronounced among those who immigrated at older ages, particularly among Hispanics and Asians. Among non-immigrants, 
Aging Studies Policy Brief

Hispanics were most likely to be living in extended family households, while among immigrants Asian older adults were the most likely to be living in extended family arrangements. This pattern contradicts what we would expect based on the health and educational characteristics of the Asian immigrants, and suggests that cultural preferences may be suppressing the level of living alone among Asian older adults. As expected, non-Hispanic white groups, both immigrant and nonimmigrant, are most likely to be living independently.

We concluded that that the other variables - income, functional limitations, and acculturation - did not explain the significant differences in living arrangements among the three groups, and we hypothesized that some aspects of the immigration experience itself might account for the differences.

Policies that give preference to family members and require sponsors to sign...affidavits of support are mechanisms that discourage independent living arrangements among immigrant elderly. Another aspect...is the cultural preferences for particular living arrangements that the immigrants bring with them from their country of origin. Together, policies regulating immigration and individual immigrants' cultural living arrangement preferences foster family and non-family living arrangements among the immigrant population by increasing family-oriented obligations. (Wilmoth et al. $1997,73)$

\section{Wilmoth 2001}

In 2001 I re-examined the same sample with many of the same variables. However, this time I used questions about self-identified race/ethnicity, place of birth, and ancestry to identify 11 immigrant groups: three non-Hispanic white groups (from North American or Western Europe, Eastern Europe, and other countries), four Hispanic groups (from Mexico, Central and South America, Cuba, and other countries), and four Asian groups (from China or Taiwan, Japan, India, or other countries). Once again Blacks and Native American Indians were excluded because there were too few for analysis. I also measured acculturation with English language proficiency and two other variables: age at immigration and year of immigration. I grouped the 
year of immigration into four categories: before 1965, 1966-1974, 1975-1984, and 1985-1990 (migration streams shifted around 1965 to Latin American and Asian countries). I hypothesized that the more recently the respondent immigrated, the less time they would have to acculturate, and the more likely they would be to live with family.

This time I divided living arrangements into three different categories from the 1997 research: living independently (alone or with spouse), living with family in the position of the householder (or head of household), and living with family not as the householder. I excluded immigrants living with nonrelatives because there were not a sufficient number to identify group differences by gender and marital status among the $11 \mathrm{racial} / \mathrm{ethnic}$ groups.

Once again, I described the characteristics of the older immigrants by gender, race/ethnicity, acculturation, income, education, and functional limitations. I also included the availability of children (children ever born) for married and unmarried women. Then I presented living arrangements for each of the 11 immigrant groups by gender and marital status and observed variations within the three general ethnoracial groups. The result indicated that unmarried Asian men from India are the least likely to live independently (27.4\%) and the most likely to live with family without being the householder (62.9\%). In contrast, more than half (56.4\%) of unmarried male immigrants from Japan live independently. This trend persisted among married men from India as well: they exhibited the highest rate of living with family without being the householder $(9.9 \%)$. Looking at unmarried female immigrants, $85 \%$ of those from India live with family without being the householder, compared to only $28.6 \%$ of those from Japan. Conversely, the highest rates of unmarried women living with family as the householder are among Hispanic groups, ranging from 17.7\% among Cuban immigrants to $25.3 \%$ among Mexican immigrants.

Obviously, there is considerable variation in the behavior of immigrant groups that is obscured when only general, Census-type ethnoracial groups are examined. Furthermore, the acculturation variables in the PUMS are not sufficient to explain the different rates of living with families: they do not directly measure, but only imply, cultural preferences. Again, more detailed information is needed. 
Aging Studies Policy Brief

\section{Wilmoth and Chen 2003}

Two years later we examined the association between living arrangements and symptoms of depression among middle-aged and older immigrants compared to non-immigrants, using cross-sectional and longitudinal data from the baseline and first two-year follow-up of the Health and Retirement Study (HRS). This data set is a nationally representative sample of 12,654 adults who were age 51 to 61 in 1992. This analysis is based on 6,391 primary respondents who were ageeligible at the baseline, of whom 5,476 were reinterviewed in the follow-up.

The HRS includes several potential mental health measures; we focused on depressive symptoms because they capture the subjective quality of life, the respondent's sense of emotional well-being. We measured four aspects of social integration, which capture the proximity of social support networks (families and friends in the neighborhood) and subjective satisfaction with these networks (or relationships). We also included variables for immigrant status (native born or immigrant, based on place of birth), three living arrangements (living alone, living with spouse only or living with spouse and family members or others, and living with family or others only), and acculturation (length of time in the United States; HRS does not ask about English language ability), as well as the usual demographic characteristics of age, gender, education, race/ethnicity (non-Hispanic white, African American or African, Hispanic, other), work status, income, and limitations in activities of daily living.

We asked two questions: Do living arrangements affect changes in depressive symptoms among immigrants and non-immigrants? Do particular living arrangements, e.g., living alone, increase the risk of depressive symptoms more among immigrants than non-immigrants?

Using bivariate analysis, we concluded that immigrants have significantly more depressive symptoms than non-immigrants, and that immigrant status and living arrangements appear to interact to influence depressive symptoms. Overall, those who live alone or with family and others have more depressive symptoms than those living with a spouse. Immigrants who live alone or with family or others have higher levels of depressive symptoms than nonimmigrants. Immigrants living alone or with family or others have the highest level of depressive symptoms, 
while non-immigrants living with a spouse have the lowest level of depressive symptoms.

Using cross-sectional and longitudinal multivariate analysis, we looked more closely at the interactions of variables and the effect of time. Among other things, the results confirm the systematic increase in depressive symptoms associated with living alone, particularly for immigrants. We speculated that, given the cultural expectation of extended family households among immigrant populations, older immigrants may be dissatisfied with living alone because it does not meet their expectations regarding later life living arrangements. However, coresidence can place its own stresses on immigrants' mental health by straining interpersonal relationships among older immigrants with one set of cultural expectations, and poor English language skills, who are living with a younger, more acculturated generation. But we emphasized, once again, the need to collect data among specific immigrant populations to "illuminate how the diversity across and within immigrant groups shapes mental health outcomes. Such analyses, in combination with this one, will provide insight into developing interventions that can improve the mental health of nativeborn and immigrant populations" (Wilmoth and Chen 2003, S313).

\section{Other Research on Older Immigrants}

- In 2001 the Journal of Gerontological Social Work dedicated an issue to Asian American elders, noting that the Asian American population grew $52.4 \%$ between 1990 and 2000, second only to the Hispanic growth rate of $57.9 \%$ for the same period. The editor wrote:

Despite the dramatic changing demographics, the internal heterogeneity of the Asian American elder population has made it difficult for researchers to conduct large-scale ethnogerontological studies that could be generalized to all Asian American elders....Lack of an accumulated knowledge base means lack of understanding of this group of elders, with its diverse ethnic/cultural, socioeconomic, and other characteristics, and thus, inadequate and ineffectual provision of services. In these circumstances, both researchers and practitioners face a daunting task of identifying strengths, deficits, needs, and culturally appropriate interventions and service-delivery models for 


\section{Aging Studies Policy Brief}

the growing number of Asian American elders and their families....[T] he lack of coverage of other major ethnic groups such as Filipino American elders, Southeast Asian elderly groups other than Vietnamese elders, and Pacific Islander elders, as well as the limited topical areas dealt with in this volume also serve as a reminder of the need to continuously encourage researchers and practitioners to contribute to building the knowledge and skills base.

(Choi 2001, 2, 3)

- Angel, Angel, and Markides (2000) used the NIA-funded Hispanic Established Population for Epidemiologic Studies of the Elderly (HEPESE), a representative sample of 3,050 Mexican Americans aged 65 and over who reside in the Southwest, to examine "the consequences of the age at which older Mexican-origin individuals immigrated to the United States on changes in their living arrangements over a two-year period, and second, the predictors of their household headship status at the end of that period. They discussed the unwillingness among Hispanic families to use nursing homes for long-term care of older persons and suggested that

[W] must begin to understand how the [Mexican American] elderly and their families cope with declining health....It is important to get some idea of whether in the future these individuals, despite physical frailty and financial difficulties, will continue to stay in the community. Additionally, it will be important to identify those family and community factors that allow them to do so. (ibid.)

- Pang et al. (2003) reported "a qualitative analysis of health-seeking behaviors of community-dwelling elderly Chinese Americans on the influences of family network, cultural values, and immigrant experience in their use of health resources." Among other things they observed that while parents reported their children no longer practiced the classical forms of filial piety, nevertheless they did not have problems getting help from their sons and daughters on request.

This group of participants did not attribute any of these changes to the immigrant experience per se. There were no observations that filial piety was diminished compared 
with what it had been before immigration; nor were there any comments suggesting that their contemporaries who stayed in China or Taiwan were the beneficiaries of traditional values....We speculate that the responses of elders in this study may reflect greater acculturation than would have been anticipated....and that a shift from 'filial piety' to 'filial autonomy' even among older immigrants may well be underway.

- Gay Becker's (2002) study of how older Cambodian Americans and Filipino Americans view their homeland in old age as they contemplate death is a fascinating glimpse of philosophies and experiences with which most of us are unfamiliar. For example, most of the Cambodian Americans in the study had lived through the Communist Khmer Rouge regime, when $20 \%$ of the population ( 1.5 million people out of 8 million) died of starvation or were murdered in the "killing fields." Most of them wanted to return to Cambodia, either for a visit or permanently. "Cambodian Americans are living in exile from their homeland, and the loss of their homeland and their disrupted lives means that for many, they are simply waiting to die to be reborn." But Becker points out that "whether or not they desired to return to the homeland to die was mediated by the presence or absence of the extended family, memories of the homeland, and the availability of traditional ritual practices in the United States."

\section{Recommendations}

As Gelfand (1994) has noted, "Although there is a substantial literature on the problems of immigrants, the issues faced by older immigrants have been for the most part neglected." My research has attempted to address this gap in the literature by using nationally representative data to examine differences in living arrangements among older immigrants and consider how these living arrangements are related to depressive symptoms. Other researchers have documented the experience of older immigrants in specific ethnic groups. Taken together, this recent research has begun to provide some insight into the unique issues faced by older immigrants.

One such issue is the potential lack of social integration, particularly for immigrants who arrive later in life and those who live alone. Living in an ethnic enclave can help to maintain continuity for the older 
Aging Studies Policy Brief

immigrant but at the same time can isolate the older adult from the broader community, including local health and social service providers. This can be potentially detrimental to an older immigrant's physical and mental well-being. This problem is compounded by the fact that immigrants experience a variety of barriers to treatment and receipt of services. Consequently mental and physical health problems are often not sufficiently treated in this population (Gelfand and Yee 1991; Mui 1998). Service providers need to be aware of the barriers older immigrants face, which are often related to poor English-language skills, and develop interventions that acknowledge the unique needs of native born and immigrant populations. Service providers would also benefit from additional research within specific immigrant groups, which would provide information that would enable them to develop appropriate and effective interventions.

This research also provides insight into the future distribution of living arrangements among the older population. It can not be assumed that the proportion of older adults living alone will continue to increase in the future. Given the propensity of living with family among minority and immigrant groups, the distribution of living arrangements among future older adult cohorts could be considerably different from those of current cohorts. As minority and immigrant populations grow, the proportion of older adults living in extended family arrangements could increase. If immigrants continue to have limited access to social welfare programs and sponsoring families have to assume additional responsibility, then extended family living arrangements could become even more prevalent. Given this, future research should monitor changes in the distribution of living arrangement among older immigrants and assess the impact these living arrangements have on the well-being of older immigrants and their families. 
Janet M. Wilmoth

\section{Bibliography}

Angel, Jacqueline L., Ronald J. Angel, and Kyriakos S. Markides. 2000. "Late-Life Immigration, Changes in Living Arrangements, and Headship Status among Older MexicanOrigin Individuals." Social Science Quarterly 8 (1) (March): 389-403.

Angus, James S. 1998. "Testimony of Acting Executive Director, Office of Naturalization Operations, Concerning Naturalization Application Caseload." Washington, DC: U.S. Department of Homeland Security. Citizenship and Immigration Services. March 18. http://uscis.gov/graphics/aboutus/congress/ testimonies/1998/980319.pdf.

Becker, Gay. 2002. "Dying Away From Home: Quandaries of Migration for Elders in Two Ethnic Groups." Journal of Gerontology: Social Sciences 57B (2) (March): S79-S95.

Casado, Banghwa Lee, and Patrick Leung. 2001. "Migratory Grief and Depression Among Elderly Chinese American Immigrants." Journal of Gerontological Social Work 36 (1-2): 5-26.

Choi, Namkee G. 2001. "Introduction [to special volume on Asian American elders]." Journal of Gerontological Social Work 36 (1-2): 1-3.

Chung, Irene. 2003. "The Impact of the 9/11 Attacks on the Elderly in NYC Chinatown: Implications for Culturally Relevant Services." Journal of Gerontological Social Work 40 (4): 3753.

Espenshade, Thomas J., and Haishan Fu. 1997. "An Analysis of English-Language Proficiency among U.S. Immigrants." American Sociological Review 62 (2) (April): 288-305.

Fennelly, Katherine, and Nicole Palasz. 2003. "English Language Proficiency of Immigrants and Refugees in the Twin Cities Metropolitan Area." International Migration 41 (5) (December): 93-125. 
Aging Studies Policy Brief

Gelfand, Donald E. 1994. Aging and Ethnicity: Knowledge and Services. New York: Springer Publishing Company.

Gelfand, Donald, and Barbara W.K. Yee. 1991. "Trends and Forces: Influence of Immigration, Migration and Acculturation on the Fabric of Aging in America. Generations 15(4): 7-10

General Accounting Office. 2004. "Immigration Benefits: Eleventh Report Required by the Haitian Refugee Immigration Fairness Act of 1998." GAO-04-1030R. Washington, DC: U. S. Government Printing Office. August 13. http://www.gao.gov/ new.items/d041030r.pdf.

George, Linda K. 1996. "Social Factors and Illness.” In Robert H. Binstock and Linda K. George (eds.), Handbook of Aging and Social Sciences. San Diego: Academic Press, pages 229-252.

Grieco, Elizabeth M., and Rachel C. Cassidy. 2001. "Overview of Race and Hispanic Origin: 2000." C2KBR/01-1. Washington, DC: U. S. Census Bureau. Census 2000 Brief. Census 2000 Brief. March. http://www.census.gov/prod/2001pubs/c2kbr01-1.pdf.

Iceland, John, Daniel H. Weinberg, and Erika Steinmetz. 2002. "Racial and Ethnic Residential Segregation in the United States: 19802000." CENSR-3. Washington, DC: U. S. Census Bureau. Census 2000 Special Reports. Census 2000 Special Reports. August. http://www.census.gov/hhes/www/housing/resseg/ pdf/censr-3.pdf.

Institute of Medicine. 2002. Unequal Treatment: Confronting Racial and Ethnic Disparities in Health Care. Washington, DC: National Academy Press. http://www.nap.edu/books/ 030908265X/html/.

Kim, Eunja, Douglas A. Kleiber, and Nancy Kropf. 2001. "Leisure Activity, Ethnic Preservation, and Cultural Integration of Older Korean Americans." Journal of Gerontological Social Work 36 (1-2): 107-129.

Lapham, Susan J., Patricia Montgomery, and Debra Niner. 1993. "We the American Foreign Born." Washington, DC: U. S. Bureau of 
the Census. We the American Series. We the American Series. September. http://www.census.gov/apsd/wepeople/we-7.pdf.

Larsen, Luke J. 2004. "The Foreign-Born Population in the United States: March 2003." Report No. P20-551. Washington, DC: U. S. Census Bureau. Current Population Reports. Current Population Reports. August. http://www.census.gov/prod/ 2004pubs/p20-551.pdf.

Lee, Gary R., Julie K. Netzer, and Raymond T. Coward. 1995. "Depression among Older Parents: The Role of Intergenerational Exchange." Journal of Marriage and Family 57 (3) (August): 823-833.

Malone, Nolan, Kaari F. Baluja, Joseph M. Costanzo, and Cynthia J. Davis. 2003. "The Foreign Born Population: 2000." C2KBR34. Washington, DC: U. S. Census Bureau. Census 2000 Brief. Census 2000 Brief. December. http://www.census.gov/prod/ 2003pubs/c2kbr-34.pdf.

Meyer, Julie. 2001. “Age: 2000.” C2KBR/01-12. Washington, DC: U. S. Census Bureau. Census 2000 Brief. Census 2000 Brief. October. http://www.census.gov/prod/2001pubs/c2kbr0112.pdf.

Modern Language Association. 2004. "MLA Interactive Language Map of Languages Spoken in the United States [based on Census 2000 data]." New York. Accessed October 31, 2004. Available from http://www.mla.org/census_map.The MLA Language Map displays the locations and numbers of speakers of the thirty languages most commonly spoken in the United States.

Mui, Ada C. 1998. "Living Alone and Depression Among Older Chinese Immigrants." Journal of Gerontological Social Work 30 (3-4): 147-155.

Pang, Elaine C., Maryalice Jordan-Marsh, Merril Silverstein, and Michael Cody. 2003. "Health-Seeking Behaviors of Elderly Chinese Americans: Shifts in Expectations." Gerontologist 43 (6) (December): 864-875. 
Aging Studies Policy Brief

Perry, Marc J. Mackun Paul J., Josephine D. Baker, Colleen D. Joyce, Lisa R. Lollock, and Lucinda S. Pearson. 2001. "Population Change and Distribution: 1990 to 2000." C2KBR/01-2. Washington, DC: U. S. Census Bureau. Census 2000 Brief. Census 2000 Brief. April. http://www.census.gov/prod/ 2001pubs/c2kbr01-2.pdf.

Pillemer, Karl, Nina Glasgow, Phyllis Moen, and Elaine Wethington, (eds.). 2000. Social Integration in the Second Half of Life. Baltimore: Johns Hopkins Press.

Pritchard, Justin. 2004. "Immigrants Outlive U.S.-Born Residents by Years." Associated Press, May 26.

Rosow, Irving. 1967. Social Integration of the Aged. New York: Free Press.

Shibusawa, Tazuko, and Ada C. Mui. 2001. "Stress, Coping, and Depression Among Japanese American Elders." Journal of Gerontological Social Work 36 (1-2): 63-81.

Shin, Hyon B., and Rosalind Bruno. 2003. "Language Use and EnglishSpeaking Ability: 2000.” C2KBR-29. Washington, DC: U. S. Census Bureau. Census 2000 Brief. Census 2000 Brief. October. http://www.census.gov/prod/2003pubs/c2kbr-29.pdf.

Singh, Gopal K., and Barry A. Miller. 2004. "Health, Life Expectancy, and Mortality Patterns Among Immigrant Populations in the United States." Canadian Journal of Public Health 95 (3) (May-June): I-14-I-21.

Stokes, Sandy Chen, Larry W. Thompson, Susan Murphy, and Gallagher-Thompson. 2001. "Screening for Depression in Immigrant Chinese-American Elders: Results of a Pilot Study." Journal of Gerontological Social Work 36 (1-2): 27-44.

U.S. Citizenship and Immigration Services. 2004. "U. S. Immigration Preference System." Washington, DC. Last updated on June 25, 2004. Available from http://uscis.gov/graphics/ glossary3.htm\#permanent.

U.S. Department of Health and Human Services. Administration on Aging. 2004. "Civil Rights. Non Citizens. Benefits for Non- 
Citizens and Other Welfare Reform Implementation Issues." Washington, DC. Accessed October 13, 2004. Last updated on 09/09/2004. Available from http://www.aoa.gov/prof/ civil_rights/Non_citizens/non_citizens_pf.asp.

U.S. Department of Health and Human Services. Center for Disease Control. 2004. "Health United States, 1990." Atlanta, GA: CDC. http://www.cdc.gov/nchs/data/hus/hus90.pdf.

U.S. Department of Health and Human Services. Center for Disease Control. 1991. "Health United States, 1990." Atlanta, GA: CDC. http://www.cdc.gov/nchs/data/hus/ hus90.pdf. The federal government's policy for health data purposes changed significantly, as announced in this publication: "Studies of minority health in the United States have focused on the black population. This chartbook expands that focus by comparing selected health indicators among several minority groups with particular emphasis on the following groups: Asian and Pacific Islanders, Americn Indians and Alaskan Natives, black Americans, and persons whose ethnic origin is Hispanic, including Mexican Americans, Cubans, and Puerto Ricans....Topics for inclusion in the chartbook were generally chosen with these criteria in mind: (a) coverage in Health People 2000; (b) relevance to minority populations; and (c) availability of data for minority populations in addition to black."

U.S. Department of Health and Human Services. Office of the Surgeon General. 2001. "Mental Health: Culture, Race, and Ethnicity." Washington, DC: Government Printing Office. http://www.mentalhealth.org/cre/toc.asp.

U.S. Department of Homeland Security. 2004a. Yearbook of Immigration Statistics, 2003. Washington, DC: U.S. Government Printing Office. http:/uscis.gov/graphics/shared/ aboutus/statistics/2003Yearbook.pdf.

U.S. Department of Homeland Security. Citizenship and Immigration Services. 2004b. "How Do I File an Affidavit of Support for a Relative?" Accessed October 19, 2004. Last updated on 
Aging Studies Policy Brief

3/31/2004. Available from http://uscis.gov/graphics/howdoi/ affsupp.htm.

U.S. Immigration and Naturalization Service. Office of Policy and Planning. 2003. "Estimates of the Unauthorized Immigrant Population Residing in the United States: 1990 to 2000 ." January. http://uscis.gov/graphics/shared/aboutus/statistics/ Ill_Report_1211.pdf.

Vialet, Joyce C. 1997. "Immigration: Reasons for Growth, 1981-1995." 97-230 EPW. Washington, DC: Congressional Research Service. Library of Congress. February 12. http://www.ncseonline.org/NLE/crsreports/population/pop2.cfm.

Wasem, Ruth Ellen. 2003. "Immigration and Naturalization Fundamentals.” Order Code RS20916. Washington, DC: Congressional Research Service. Library of Congress. Updated May 20. http://fpc.state.gov/documents/organization/ 34520.pdf.

Wilmoth, Janet M. 2001. "Living Arrangements Among Older Immigrants in the United States." Gerontologist 41 (2) (April): 228-238.

Wilmoth, Janet M., and Pei-Chun Chen. 2003. "Immigrant Status, Living Arrangements, and Depressive Symptoms Among Middle-Aged and Older Adults." Journals of Gerontology: Social Sciences 58B (5) (September): S305-S313.

Wilmoth, Janet M., Gordon F. De Jong, and Christine L. Himes. 1997. "Immigrant and Non-Immigrant Living Arrangements Among America's White, Hispanic, and Asian Elderly Population." International Journal of Sociology and Social Policy 17 (9/10): 57-82. 